\title{
Role of diacylglycerol O-acyltransferase (DGAT) isoforms in bovine hepatic fatty acid metabolism
}

\author{
Wei Yang, ${ }^{1 *} \odot$ Shuang Wang, ${ }^{1 *}$ Juan J. Loor, ${ }^{2} \odot$ Matheus G. Lopes, ${ }^{2} \odot$ Yingying Zhao, ${ }^{1} \odot$ Xinru Ma, ${ }^{1} \odot$

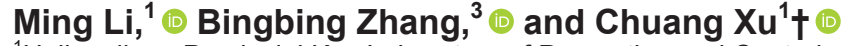 \\ ${ }^{1}$ Heilongjiang Provincial Key Laboratory of Prevention and Control of Bovine Diseases, College of Animal Science and Veterinary Medicine, \\ Heilongjiang Bayi Agricultural University, Daqing 163319, China \\ ${ }^{2}$ Mammalian NutriPhysioGenomics, Department of Animal Sciences and Division of Nutritional Sciences, University of Illinois, Urbana 61801 \\ ${ }^{3}$ College of Life Science and Technology, Heilongjiang Bayi Agricultural University, Daqing 163319, China
}

\section{ABSTRACT}

Fatty acid accumulation in hepatocytes induced by high concentrations of fatty acids due to lipolysis and the associated oxidative damage they cause occur most frequently after calving. Because of their role in esterification of fatty acids, diacylglycerol acyltransferase isoforms (DGAT1 and DGAT2) could play a role in the susceptibility of dairy cows to develop fatty liver. To gain mechanistic insights, we performed in vivo and in vitro analyses using liver biopsies or isolated primary hepatocytes. The in vivo study $(\mathrm{n}=5$ cows/group) involved healthy cows [average liver triacylglycerol $(\mathrm{TAG})=0.78 \% ; 0.58$ to $0.93 \%$, ratio of triglyceride weight to wet liver weight] or cows diagnosed with fatty liver (average $\mathrm{TAG}=7.60 \%$; 5.31 to $10.54 \%$ ). In vitro, hepatocytes isolated from 3 healthy female calves $(1 \mathrm{~d}$ old, 44 to $53 \mathrm{~kg}$ ) were challenged with (fatty acids) or without (control) a $1.2 \mathrm{mM}$ mixture of fatty acids in an attempt to induce metabolic stress. Furthermore, hepatocytes were treated with DGAT1 inhibitor or DGAT2 inhibitor for $2 \mathrm{~h}$ followed by a challenge with (DGAT1 inhibitor + fatty acids or DGAT2 inhibitor + fatty acids) or without (DGAT1 inhibitor or DGAT2 inhibitor) the $1.2 \mathrm{mM}$ mixture of fatty acids for $12 \mathrm{~h}$. Data analysis of liver biopsies was compared using a 2-tailed unpaired Student's $t$-test. Data from calf hepatocyte treatment comparisons were assessed by one-way ANOVA, and multiplicity for each experiment was adjusted by the Holm's procedure. Data indicated that both fatty liver and in vitro challenge with fatty acids were associated with greater mRNA and protein abundance of SREBF1, FASN, DGAT1, and DGAT2. In contrast, mRNA and

Received August 11, 2021.

Accepted December 23, 2021

*These authors contributed equally to this study.

†Corresponding author: xuchuang7175@163.com protein abundance of CPT1A and very low-density lipoprotein synthesis-related proteins MTTP and APOB were markedly lower. However, compared with fatty acid challenge alone, DGAT1 inhibitor + fatty acids led to greater mRNA and protein abundance of CPT1A and APOB, and greater mRNA abundance of SREBF1 and MTTP. Furthermore, this treatment led to lower mRNA abundance of FASN and DGAT2 and TAG concentrations. Compared with fatty acid challenge alone, DGAT2 inhibitor + fatty acids led to greater mRNA and protein abundance of CPT1A, MTTP, and APOB, and lower mRNA and protein abundance of SREBF1 and FASN. In addition, compared with control and fatty acids, there was greater protein abundance of GRP78 and PERK in both DGAT1 and DGAT2 inhibitor with or without fatty acids. Furthermore, compared with control and fatty acids, reactive oxygen species concentrations in the DGAT1 inhibitor with or without fatty acid group was greater. Overall, data suggested that DGAT1 is particularly relevant in the context of hepatocyte TAG synthesis from exogenous fatty acids. Disruption of both DGAT1 and DGAT2 altered lipid homeostasis, channeling fatty acids toward oxidation and generation of reactive oxygen species. Both DGAT isoforms play a role in promoting fatty acid storage into TAG and lipid droplets to protect hepatocytes from oxidative damage.

Key words: dairy cow, fatty liver, lactation, metabolism

\section{INTRODUCTION}

Negative energy balance (NEB) is a state commonly experienced by peripartal dairy cows due to insufficient DMI to sustain increased energy requirements for milk production (Grummer, 2007; Loor et al., 2013). Depending on the severity of NEB, fatty acids produced during adipose tissue mobilization could cause increased triacylglycerol (TAG) accumulation in the liver and lead to the occurrence of fatty liver (Murondoti et al., 2004; 
Shahsavari et al., 2016). Despite extensive research over the past decades, cellular mechanisms controlling the fate of fatty acids flowing into the liver during conditions such as NEB or fatty liver are not fully known.

Within the liver, transport of incoming fatty acids into the mitochondria via CPT1 for $\beta$-oxidation is a key pathway that reduces esterification of fatty acids, which leads to formation of TAG that can be used to synthesize very low-density lipoprotein (VLDL) for export (van den Top et al., 1996; Zhu et al., 2019). Available research indicates that accumulation of TAG is linked primarily to the inherently low rate of VLDL secretion in ruminants (Bauchart et al., 1996; Coleman et al., 2019). However, recent molecular data also suggest that a lipogenic program can be activated during conditions in which fatty acid supply to the liver increases markedly (Zhu et al., 2019).

The lipoprotein VLDL is the main route of endogenous TAG transport from the liver and plays an important role in lipid homeostasis in humans, rodents, and cattle (Katoh, 2002; Yli-Jokipii et al., 2003). First, the endoplasmic reticulum synthesizes TAG and transfers it to microsomal triglyceride transfer protein (MTTP) and then to nascent apolipoprotein B (APOB) as it is being translated within the lumen of the rough endoplasmic reticulum (Sturley and Hussain, 2012). After these nascent VLDL molecules are fully lipidated with TAG, they exit the endoplasmic reticulum and travel to the Golgi apparatus where the final steps of VLDL formation are completed (Sturley and Hussain, 2012). As an important raw material for VLDL synthesis, synthesis of TAG is regulated partly by the terminal enzymes in the pathway, DGAT1 and DGAT2 in mouse (Yu et al., 2002). Although DGAT2 is mainly expressed in hepatocytes where they catalyze TAG synthesis, DGAT1 is also expressed and can play an important role in TAG synthesis and VLDL assembly (Takahashi et al., 2007; Ying et al., 2017).

In nonruminants, it has been proposed that DGAT1 and DGAT2 differ in their respective preferences for pools of a fatty acid substrate (i.e., exogenous versus endogenous) with DGAT1 utilizing exogenous fatty acids and DGAT2 de novo synthesized fatty acids for TAG synthesis (Qi et al., 2012; McLaren et al., 2018; Zoni et al., 2021). Simultaneous inhibition of DGAT1 and DGAT2 led to a loss of cardiac TAG synthesis ability and enhanced lipotoxicity (Cheng et al., 2020). Thus, one aim of the present study was to elucidate expression characteristics of DGAT1, DGAT2, and related pathways in liver from dairy cows diagnosed with fatty liver. Another aim was to use primary calf hepatocytes to investigate specific functions of DGAT1 and DGAT2 in the context of fatty acid metabolism.

\section{MATERIALS AND METHODS}

The study protocol was approved by the Ethics Committee for the Use and Care of Animals, Heilongjiang Bayi Agricultural University (Daqing, China).

\section{Liver Tissue Collection}

Twenty-six lactating multiparous Holstein cows $(8 \pm$ 2 d postpartum, parity $2.5 \pm 0.50$, BCS $3.06 \pm 0.11)$ from a commercial dairy farm (Heilongjiang Province, China), housed in freestall barn with concrete stalls bedded with sawdust, fed ad libitum (Supplemental Table S1, https://figshare.com/s/ee162ac77b6746511f41), received a routine physical examination by the attending veterinarian before selection for the study to ensure blood BHB $<1.2 \mathrm{mmol} / \mathrm{L}(\mathrm{n}=10$ cows $)$ or $\geq 3.0$ $\mathrm{mmol} / \mathrm{L}(\mathrm{n}=16 \mathrm{cows})$ and there were no other clinical disorders. Briefly, blood samples of each cow were collected on the morning before feeding by venipuncture of the caudal vein and heparin sodium was used as an anticoagulant. Blood BHB were immediately measured by cow blood ketone meter (TNN-2, Yicheng Bioelectronics Technology Co. Ltd.). Then, blood samples were centrifuged at $1,400 \times g$ for $10 \mathrm{~min}$ at $4^{\circ} \mathrm{C}$. The plasma parameters, including fatty acids, glucose, and aspartate aminotransferase, were measured by a biochemical kit (Beijing Jiuqiang Biotechnology Co. Ltd.) with an automatic clinical analyzer (Synchron DXC800; Beckman Coulter Inc.). After blood collection, liver biopsies were conducted with an 18-gauge biopsy probe (EMENT-1815, Shenzhen Yiman Technology Co., Ltd.) as described previously (Vailati Riboni et al., 2015; Coleman et al., 2019). The liver biopsy specimens were immediately stored at $-80^{\circ} \mathrm{C}$ for TAG analysis using an enzymatic kit (Applygen Technologies Inc.). Cows with liver TAG content lower than $1 \%$ (expressed as the ratio of triglyceride weight to wet liver weight) were classified as healthy and those with liver TAG content greater than $2 \%$ as mild fatty liver (Bobe et al., 2004). Milk yield was obtained from the farm milk recording system. Subsequently, 5 cows with average liver TAG $=7.60 \%$ (5.3 to $10.5 \%$ ), milk yield $29.3 \mathrm{~kg}$ (21.3 to 38.6 $\mathrm{kg}), \mathrm{BHB}=3.66 \mathrm{mmol} / \mathrm{L}(3.1$ to $4.2 \mathrm{mmol} / \mathrm{L})$, serum fatty acids $=1.24 \mathrm{mmol} / \mathrm{L}(0.91$ to $1.48 \mathrm{mmol} / \mathrm{L})$, serum glucose $=2.11 \mathrm{mmol} / \mathrm{L}(1.90$ to $2.43 \mathrm{mmol} / \mathrm{L})$, and serum aspartate aminotransferase $=199.4 \mathrm{U} / \mathrm{L}$ (117 to $319 \mathrm{U} / \mathrm{L}$ ) were chosen as the fatty liver group. Another 5 cows with average liver TAG $=0.78 \%(0.58$ to $0.93 \%)$, milk yield $36.6 \mathrm{~kg}$ ( 31.5 to $42.5 \mathrm{~kg}$ ), blood $\mathrm{BHB}=0.90 \mathrm{mmol} / \mathrm{L}(0.7$ to $1.1 \mathrm{mmol} / \mathrm{L})$, serum fatty acids $=0.534 \mathrm{mmol} / \mathrm{L}(0.43$ to $0.62 \mathrm{mmol} / \mathrm{L})$, serum glucose $=3.19 \mathrm{mmol} / \mathrm{L}(2.81$ to $3.69 \mathrm{mmol} / \mathrm{L})$, and 
serum aspartate aminotransferase $=88.4 \mathrm{U} / \mathrm{L}(82$ to 94 $\mathrm{U} / \mathrm{L})$ were chosen as healthy controls.

\section{Isolation and Culture of Primary Calf Hepatocytes}

Three newborn healthy female Holstein calves (1 d old, 44 to $53 \mathrm{~kg}$ ) were anesthetized with thiamylal sodium $(50 \mathrm{mg} / \mathrm{kg})$ followed by intravenous heparin $(1,500 \mathrm{IU} / \mathrm{kg})$ injection. Primary hepatocytes were isolated using a 2-step collagenase perfusion method as previously described (Du et al., 2018b; Zhang et al., 2020a). Briefly, the caudate lobe was isolated and washed with perfusion solution. The perfusion solution A $(140 \mathrm{~m} M \mathrm{NaCl}, 6.7 \mathrm{~m} M \mathrm{KCl}, 10 \mathrm{~m} M$ HEPES, 2.5 $\mathrm{m} M$ glucose, and $0.5 \mathrm{~m} M$ EDTA; $\mathrm{pH} 7.4 ; 37^{\circ} \mathrm{C} ; 50 \mathrm{~mL} /$ min for $10-15 \mathrm{~min}$ ) preheated at $37^{\circ} \mathrm{C}$ was used to rinse the blood surface of the caudate process surface, and vascular intubation for perfusion. The liver was then perfused with the same flow rate of $37^{\circ} \mathrm{C}$ pre-warmed perfusion solution $\mathrm{B}(140 \mathrm{mM} \mathrm{NaCl}, 6.7 \mathrm{mM} \mathrm{KCl}, 30$ $\mathrm{m} M$ HEPES, $2.5 \mathrm{~m} M$ glucose, and $5 \mathrm{~m} M \mathrm{CaCl}_{2} ; \mathrm{pH}$ 7.4; $37^{\circ} \mathrm{C} ; 50 \mathrm{~mL} / \mathrm{min}$ for $5 \mathrm{~min}$ ) through blood vessels until the liquid became clear. The liver was then perfused with perfusion solution B with $0.0002 \mathrm{~g} / \mathrm{mL}$ collagenase IV (Type IV Collagenase, Gibco) through blood vessels until the liquid became turbid. Fetal bovine serum (FBS; Hyclone Laboratories) was added to terminate the digestion. Upon removal of the liver capsule, blood vessels, fat, and connective tissue, the shredded liver tissue was resuspended in $4^{\circ} \mathrm{C}$ pre-cooled RPMI1640 medium and filtered sequentially with 100 mesh (150 $\mu \mathrm{m})$ and 200 mesh $(75 \mu \mathrm{m})$ cell sieves. The obtained hepatocytes were washed twice with RPMI-1640 basal medium (Hyclone Laboratories) and centrifuged for 5 min at $500 \times g$ at $4^{\circ} \mathrm{C}$. Primary hepatocytes $\left(1 \times 10^{6}\right.$ cells $/ \mathrm{mL}$ ) were seeded into a 6 -well tissue culture plate using adherent medium (RPMI-1640 basic medium supplemented with $10 \% \mathrm{FBS}, 10^{-6} \mathrm{~mol} / \mathrm{L}$ of insulin, $10^{-6} \mathrm{~mol} / \mathrm{L}$ of dexamethasone, $10 \mu \mathrm{g} / \mathrm{mL}$ of vitamin $\mathrm{C}$ ) and incubated at $37^{\circ} \mathrm{C}$ in $5 \% \mathrm{CO}_{2}$ for $4 \mathrm{~h}$. The medium was replaced with growth medium (RPMI-1640 with $10 \%$ FBS), and growth medium was replaced every 24 h.

After $44 \mathrm{~h}$ of culture, hepatocytes ( $\mathrm{n}=6$ replicates per group) were starved for $12 \mathrm{~h}$ in serum-free RPMI1640 basal medium. Subsequently, hepatocytes were maintained in RPMI-1640 basal medium containing $2 \%$ BSA and treated with or without $1.2 \mathrm{mM}$ fatty acids (cis-9-18:1, 18:2, 16:0, 18:0, and cis-9-16:1 at 43.5, 4.9, $31.9,14.4$, and $5.3 \%$ of total fatty acids, respectively) for $12 \mathrm{~h}$. The mixing ratio and concentration of fatty acids are based on previous studies on fatty acid com- position of cows in ketosis and other in vitro studies (Yamdagni and Schultz, 1970; Li et al., 2012, 2021).

\section{Inhibition of DGAT1 and DGAT2}

Before inhibition of DGAT1 and DGAT2, hepatocytes were cultured in 6 -well plates $\left(1 \times 10^{6}\right)$ with growth medium for $44 \mathrm{~h}$. Cells $(\mathrm{n}=6$ replicates per group) were divided into 6 groups: control, fatty acids, DGAT1 inhibitor, DGAT1 inhibitor + fatty acids, DGAT2 inhibitor, DGAT2 inhibitor + fatty acids. In the DGAT1 inhibitor group (DGAT1i) and DGAT1 inhibitor + fatty acid group (DGAT1i + fatty acids), $0.3 \mu M$ DGAT1 inhibitor (DGAT1 inhibitor 2, HY50670, MCE) was used for $2 \mathrm{~h}$ before incubation with or without fatty acids. In the DGAT2 inhibitor group (DGAT2i) and DGAT2 inhibitor + fatty acid group (DGAT2i + fatty acids), $0.3 \mu M$ DGAT2 inhibitor (PF06424439 methanesulfonate, HY-108341A, MCE) was used for $2 \mathrm{~h}$ before culture with or without fatty acids.

\section{mRNA Extraction and Reverse-Transcription Quantitative PCR}

Total mRNA was extracted from liver tissue $(\mathrm{n}=$ 5 cows per group) and hepatocytes $(\mathrm{n}=6$ replicates per group) using Trizol according to the manufacturer's protocol (Invitrogen Corporation). Concentration of RNA was determined with a K5500 microspectrophotometer (Beijing Kaiao Science and Technology Development Co. Ltd.), the ratio of the optical density at $260 / 280 \mathrm{~nm}$ was 1.9 , and the $28 \mathrm{~S}$ ribosomal RNA band was approximately twice that of the $18 \mathrm{~S}$ band in the total RNA sample, indicating that isolated RNA was of high quality (Skrypina et al., 2003). One microgram of total RNA was transcribed into cDNA using Reverse Transcriptase M-MLV (RNase H-; RR047A, TaKaRa Biotechnology Co. Ltd.). The SYBR green plus reagent kit (Roche) was used to prepare a $20-\mu \mathrm{L}$ mixture and mRNA abundance was detected with a 7300 Real-Time PCR System (F. Hoffmann-La Roche AG). The reaction conditions were as follows: initial denaturation at $95^{\circ} \mathrm{C}$ for $3 \mathrm{~min}$, followed by 40 cycles of denaturation at $95^{\circ} \mathrm{C}$ for $15 \mathrm{~s}$, annealing at $60^{\circ} \mathrm{C}$ for $1 \mathrm{~min}$, and extension at $72^{\circ} \mathrm{C}$ for $30 \mathrm{~s}$; and extension at $72^{\circ} \mathrm{C}$ for $5 \mathrm{~min}$. Evaluated target genes were $S R E B F 1, F A S N, A P O B, M T T P$, DGAT1, DGAT2, CPT1A, GRP78, and PERK. Data were normalized using the geometric mean of $A C T B$ and $G A P D H$. Relative abundance was calculated using the $2^{-\Delta \Delta \mathrm{CT}}$ method. Gene primers were referenced in our previous work (Dong et al., 2019; Zhang et al., 
Yang et al.: DGAT AND LIVER FATTY ACID METABOLISM

Table 1. Sequences of primers used for real-time PCR amplification

\begin{tabular}{|c|c|c|c|}
\hline Gene & GenBank number & Primer $\left(5^{\prime}\right.$ to $\left.3^{\prime}\right)$ & Length (bp) \\
\hline$G A P D H$ & NM_001034034.2 & Forward: GTCTTCACTACCATGGAGAAGG & 197 \\
\hline$S R E B F 1$ & NM_001113302.1 & $\begin{array}{l}\text { Forward: GCAGCCCATTCATCAGCCAGACC } \\
\text { Reverse: CGACACCACCAGCATCAACCACG }\end{array}$ & 119 \\
\hline$F A S N$ & NM_001012669.1 & $\begin{array}{l}\text { Forward: ACAGCCTCTTCCTAGTTTAGACG } \\
\text { Reverse: CTCTAGCACGATCAGCTCGA }\end{array}$ & 144 \\
\hline MTTP & NM 001101834.1 & $\begin{array}{l}\text { Forward: CGTAGATAGTACCTAGCTAGGCTCTAG } \\
\text { Reverse: GGCGGCAAGGTAGGCTAATAGG }\end{array}$ & 201 \\
\hline$D G A T 1$ & XM_025001414.1 & $\begin{array}{l}\text { Forward: CCACTAGGGACCTAGAGGTAGTC } \\
\text { Reverse: GCATCACCACACACCAATTCA }\end{array}$ & 101 \\
\hline$D G A T 2$ & NM_205793.2 & $\begin{array}{l}\text { Forward: CTAGGCTAGGTAGTTTAGACTAGGA } \\
\text { Reverse: TAGCCAGGGAACTTCTTAGCTT }\end{array}$ & 239 \\
\hline
\end{tabular}

2020b) or designed using Applied Biosystems Primer Express software and are shown in Table 1.

\section{Protein Extraction and Western Blotting}

Liver tissue ( $\mathrm{n}=5$ cows per group) and hepatocytes $(\mathrm{n}=6$ replicates per group) were lysed using RIPA buffer (Beyotime Biotechnology) containing protease inhibitors, incubated on ice for $30 \mathrm{~min}$, then centrifuged at $14,000 \times g$ for $5 \mathrm{~min}$ at $4^{\circ} \mathrm{C}$, and protein measured using the BCA protein assay kit (Beyotime). Aliquots of $30 \mu \mathrm{g}$ total protein were loaded on $8 \%$ SDS polyacrylamide gels with known molecular weight markers (Solarbio Life Sciences). Subsequently, the protein was transferred onto $0.45-\mu \mathrm{m}$ polyvinylidene difluoride membranes. The polyvinylidene difluoride membranes were blocked with $5 \%$ skim milk powder in Tris-buffered saline $(50 \mathrm{~m} M$ Tris, pH 7.6, $150 \mathrm{mM} \mathrm{NaCl}$, and $0.1 \%$ Tween 20) for $1 \mathrm{~h}$ at room temperature. Membranes were cut into corresponding fragments according to the molecular weight of the protein and exposed to rabbit anti-SREBF1 (75 kDa, 1:1,000, NB100-2215; Novus), rabbit anti-FASN (273 kDa, 1:1,000, C2065; Cell Signaling), goat anti-DGAT1 (55 kDa, 1:1,000, ab122924, Abcam), rabbit anti-DGAT2 (39 kDa, 1:2,000, A13890, ABclonal), rabbit anti-CPT1A (88 kDa, $1 \mu \mathrm{g} / \mathrm{mL}$,

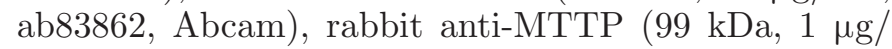
$\mathrm{mL}$, ab186446, Abcam), goat anti-APOB (460 kDa, 1:500, ab7616, Abcam), mouse anti-GRP78 (78 kDa, 1:250, sc-376768; Santa Cruz), rabbit anti-PERK (140 kDa, 1:1,000, C33E10; Cell Signaling), and mouse anti$\beta$-actin (internal control; 43 kDa, 1:1,000, sc-47778; San- ta Cruz) overnight at $4^{\circ} \mathrm{C}$, respectively. After washing and incubation with horseradish peroxidase-conjugated anti-mouse, anti-rabbit, or anti-goat antibody (Beyotime Biotechnology), respectively, for $40 \mathrm{~min}$ at room temperature, immunoreactive bands were detected by enhanced chemiluminescence (Beyotime) solution using a protein simple imager (ProteinSimple), and ImagePro Plus 6.0 software (Media Cybernetics Inc.) was used to quantify the band strength. The target protein expression was normalized to $\beta$-actin expression.

\section{TAG Content and Lipid Droplet Fluorescence Assay}

Content of TAG in liver tissue $(\mathrm{n}=5$ cows per group) and primary hepatocytes $(\mathrm{n}=6$ replicates per group) was determined using an enzymatic assay kit (Applygen Technologies Inc.) in accordance with the manufacturer's instructions. Briefly, liver tissues (about $15 \mathrm{mg}$ ) or primary hepatocytes were added to $0.1 \mathrm{~mL}$ of lysis solution and homogenized by polytron homogenizer. After standing for $30 \mathrm{~min}$ and centrifuging at $14,000 \times g$ for $5 \mathrm{~min}$ at $4^{\circ} \mathrm{C}$, an appropriate amount of supernatant was taken for subsequent experiments. The remaining liquid concentration of primary hepatocyte samples was determined using the BCA protein assay kit (Beyotime Biotechnology) for TAG content correction. For lipid droplet fluorescence, hepatocytes were washed with PBS and fixed at room temperature with $4 \%$ paraformaldehyde for $30 \mathrm{~min}$. Cellular staining was performed using BODIPY 493/503 (Invitrogen Corporation). The nucleus was stained with Hoechst (Beyotime Biotechnology) at room temperature for 8 
min. Fluorescence was determined using an inverted microscope (IX73, Olympus).

\section{Cell Culture Supernatant APOB Lipid Moiety Content Assay}

Hepatocyte culture supernatant from all treatments was collected and content of APOB lipid moiety was determined using an bovine APOB ELISA assay kit (Lengton Bioscience Co. Ltd.) in accordance with the manufacturer's instructions.

\section{Cellular Oxidative Stress Indices}

Content of malondialdehyde (MDA; Yamdagni and Schultz) in primary hepatocytes $(\mathrm{n}=6$ replicates per group) was determined with commercial kits following the manufacturer's instructions (MDA assay kit, S0131S, Beyotime Biotechnology). Changes in reactive oxygen species (ROS) in hepatocytes were determined with a commercial ROS assay kit (S0033S, Beyotime). A total of $1 \times 10^{5}$ cells were incubated with $10 \mu M$ carboxy-2' $7^{\prime}$-dichloro-dihydro-fluorescein diacetate probe in PBS for $15 \mathrm{~min}$ at $37^{\circ} \mathrm{C}$. Fluorescence was measured at $488 \mathrm{~nm}$ (excitation) and $525 \mathrm{~nm}$ (emission) by a Beckman CytoFLEX FCM (Beckman Coulter).

\section{Statistical Analysis}

The results are reported as means \pm standard error of the means. The data were analyzed by using SPSS 22.0 (IBM Corp.) or Prism 7 statistical software (GraphPad InStat Software). Data generated with liver tissue was compared using a 2-tailed unpaired Student's t-test. Data from calf hepatocyte treatment comparisons were assessed by one-way ANOVA, and multiplicity for each experiment was adjusted by the Holm's procedure to control for type I error rate at 0.05 . Differences with $P$ $<0.05$ were considered statistically significant.

\section{RESULTS}

\section{mRNA and Protein Abundance in Healthy Cows or Cows with Fatty Liver}

Relative mRNA abundance of lipid synthesis-related genes (SREBF1, FASN, DGAT1, and DGAT2; $P<$ $0.01)$ and endoplasmic reticulum stress-related genes (GRP78 and PERK) was greater in cows with fatty liver compared with healthy control cows $(P<0.01$; Figure 1A). In contrast, mRNA abundance of fatty acid oxidation- $(C P T 1 A)$ and VLDL synthesis-related (MTTP and APOB) genes was lower in cows with fatty liver compared with healthy control cows $(P<0.01$; Figure 1A).

Protein abundance of lipid synthesis-related proteins (SREBF1, FASN, DGAT1, and DGAT2) and endoplasmic reticulum stress-related proteins (GRP78 and PERK) was greater in cows with fatty liver compared with healthy control cows $(P<0.01$; Figure $1 \mathrm{C})$. In contrast, protein abundance of fatty acid oxidation (CPT1A; $P<0.01)$ and VLDL synthesis-related $[$ MTTP $(P<0.01)$ and APOB $(P<0.01)]$ proteins was lower in cows with fatty liver compared with healthy control cows (Figure 1C).

\section{Effect of Inhibition of DGAT1 and DGAT2 on Lipid Synthesis}

Compared with the control, relative mRNA and protein abundance of SREBF1, FASN, DGAT1, and DGAT2 were greater in response to $1.2 \mathrm{~m} M$ fatty acid treatment $(P<0.01$; Figure $2 \mathrm{~A}-\mathrm{C})$, whereas mRNA and protein abundance of CPT1A, MTTP, and APOB were lower $(P<0.01$; Figure $2 \mathrm{~A}-\mathrm{C})$.

As expected, inhibition of DGAT1 and DGAT2 led to lower mRNA and protein abundance of DGAT1 and DGAT2 $(P<0.01$; Figure $2 \mathrm{~A}-\mathrm{C})$. Compared with the control, relative mRNA abundance of SREBF1 $(P<$ $0.01)$ and $F A S N(P<0.01)$ was greater in cells with the DGAT1 inhibitor (Figure 2A-C). In contrast, mRNA abundance of $A P O B(P<0.01)$ and $C P T 1 A(P<0.01)$ and protein abundance of MTTP $(P<0.01)$, APOB $(P<0.01)$, and CPT1A $(P=0.047)$ were lower in cells with DGAT1 inhibitor compared with the control (Figure 2A-C).

Compared with the control, relative mRNA abundance of FASN was greater in cells with DGAT2 inhibitor $(P<0.01$; Figure $2 \mathrm{~A})$, whereas mRNA abundance of SREBF1 $(P=0.020), \operatorname{MTTP}(P<0.01)$, and CPT1A $(P<0.01)$ and protein abundance of MTTP, APOB, and CPT1A were lower in cells with DGAT2 inhibitor compared with the control $(P<0.01$; Figure $2 \mathrm{~A}-\mathrm{C})$.

Compared with the fatty acid group, mRNA abundance of SREBF1 $(P<0.01), C P T 1 A(P<0.01)$, $\operatorname{MTTP}(P<0.01)$, and $A P O B(P<0.01)$ and protein abundance of APOB $(P<0.01)$ and CPT1A $(P<$ $0.01)$ were greater in cells with DGAT1 inhibitor + fatty acids (Figure 2A-C). In contrast, mRNA abundance of FASN $(P<0.01)$ and DGAT2 $(P<0.01)$ was lower in cells with DGAT1 inhibitor + fatty acids compared with the fatty acid group (Figure $2 \mathrm{~A}-\mathrm{C}$ ).

Compared with the fatty acid group, mRNA and protein abundance of CPT1A $(P<0.01)$, MTTP $(P$ $<0.01)$, and APOB $(P<0.01)$ was greater in cells from the DGAT2 inhibitor + fatty acid group (Figure 
2A-C), whereas mRNA abundance of SREBF1 $(P<$ $0.01)$ and $F A S N(P<0.01)$ and protein abundance of FASN $(P<0.01)$ were lower in cells with DGAT2 inhibitor + fatty acids compared with the fatty acid group (Figure $2 \mathrm{~A}-\mathrm{C}$ ).

\section{Effect of Inhibition of DGAT1 and DGAT2 on Lipid Accumulation and APOB Lipid Moiety Secretion}

Concentration of TAG was greater in hepatocytes from cells incubated with fatty acids compared with the control $(P<0.01$; Figure 3A). However, hepatocytes with DGAT1 inhibitor had lower TAG concentration compared with the control $(P<0.01$; Figure $3 \mathrm{~A})$.
Concentration of TAG was lower in hepatocytes from cells with DGAT1 inhibitor + fatty acids compared with the fatty acid group $(P<0.01$; Figure 3A), whereas TAG concentration in hepatocytes from DGAT2 inhibitor + fatty acids did not differ compared with the fatty acid group (Figure 3A).

Accumulation of lipid droplets in hepatocytes was consistent with changes observed in TAG concentration (Figure 3B), and APOB lipid moiety concentration was lower in supernatant from the fatty acid compared with the control group $(P=0.014$; Figure $3 \mathrm{C})$. However, there was no change in APOB lipid moiety concentration in supernatant from cells with DGAT1 and DGAT2 inhibitor compared with the control (Figure 3C).

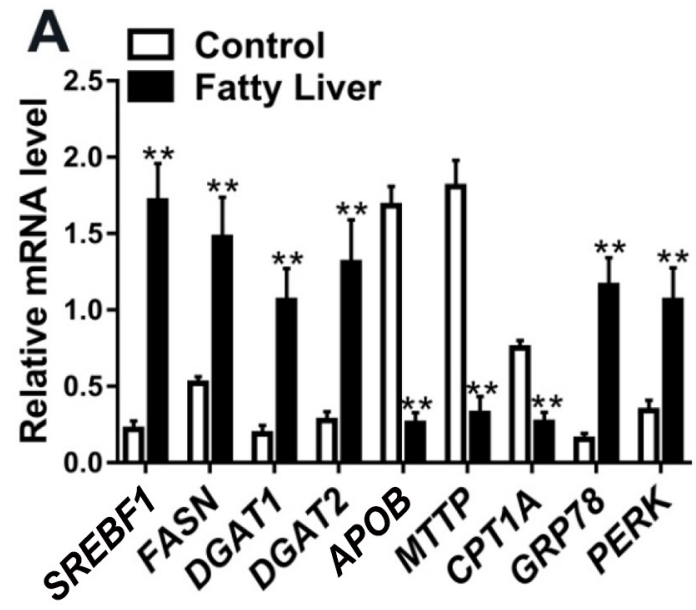

B

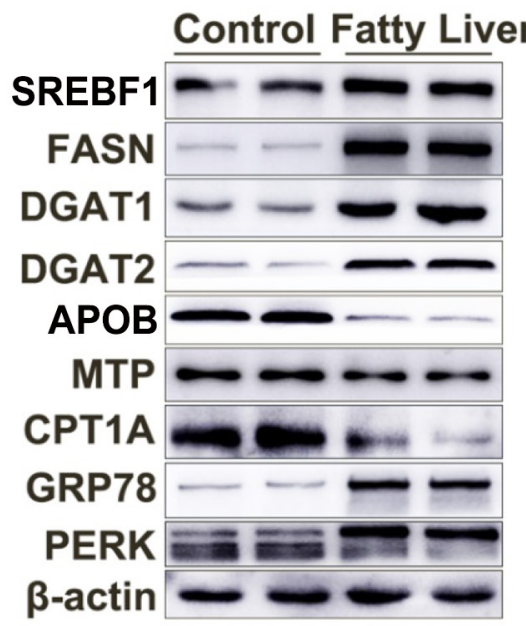

C

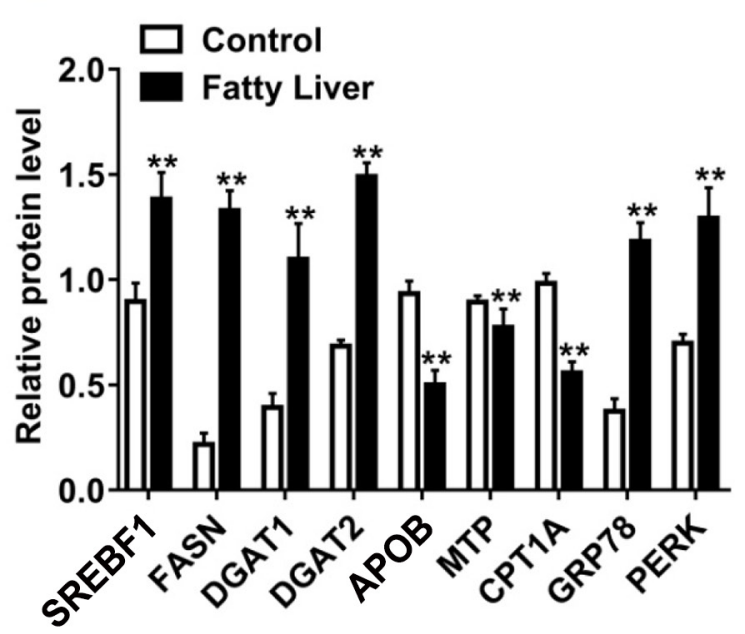

Figure 1. The effect of fatty liver on the abundance of key molecules in lipid synthesis. Liver tissue from healthy cows and cows with fatty liver was collected and decomposed. (A) Relative mRNA abundance of SREBF1, FASN, DGAT1, DGAT2, APOB, MTTP, CPT1A, GRP78, and PERK; (B) representative western blots of SREBF1, FASN, DGAT1, DGAT2, APOB, MTTP, CPT1A, GRP78, and PERK; and (C) relative protein abundance of SREBF1, FASN, DGAT1, DGAT2, APOB, MTTP, CPT1A, GRP78, and PERK. Comparisons among groups were calculated using a one-way ANOVA with a Duncan correction. The data presented are the mean $\pm \mathrm{SEM} ;{ }^{* *} P \leq 0.01$ 

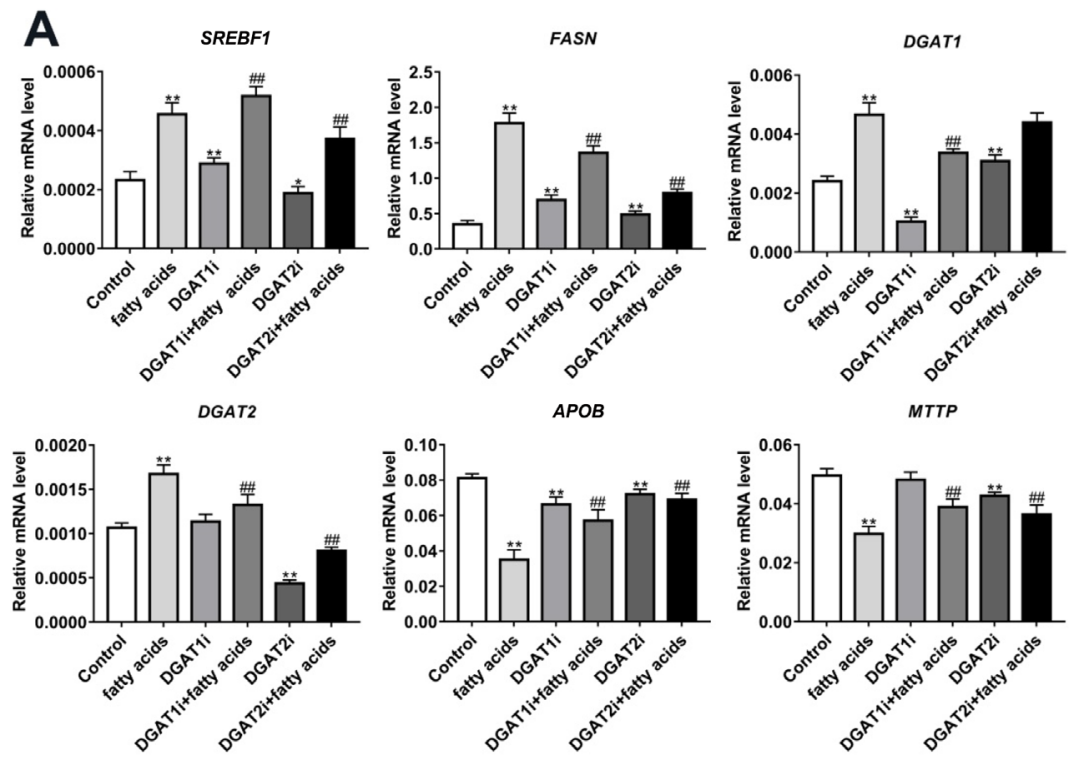

CPT1A
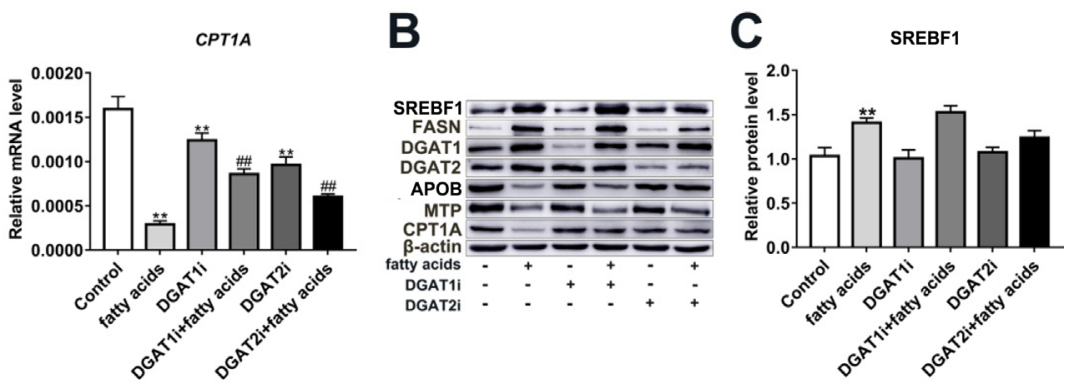

FASN

DGAT1
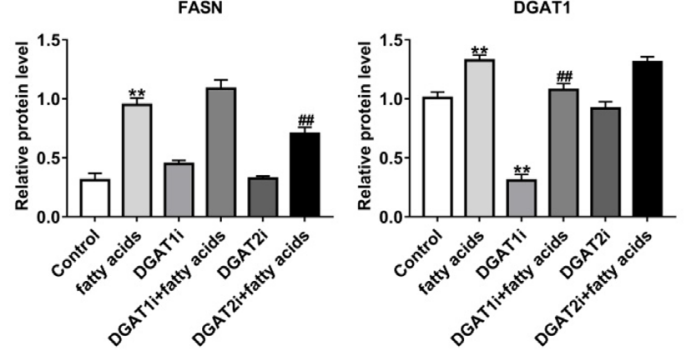

DGAT2

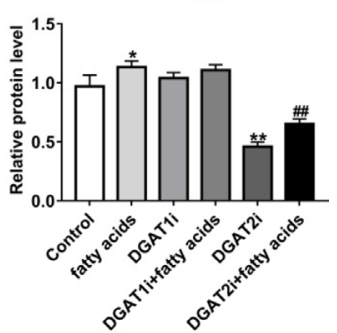

MTTP
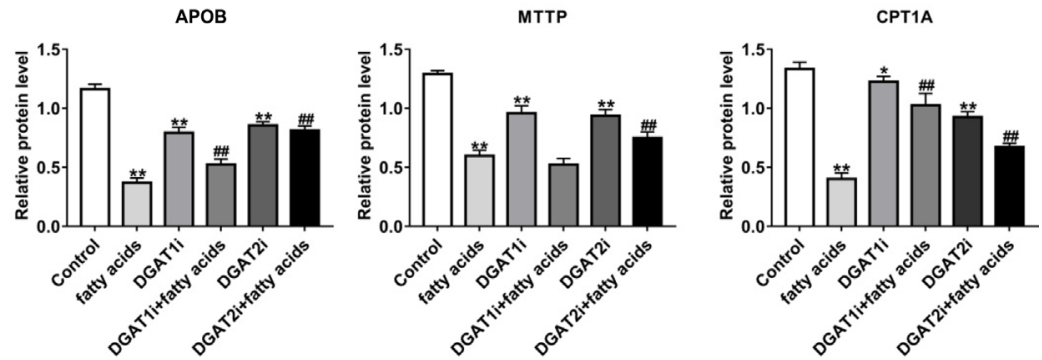

Figure 2. The effect of DGAT1 and DGAT2 inhibitor on lipid synthesis in calf primary hepatocytes. Treatments were a control group (cells cultured in RPMI-1640 basic medium for $12 \mathrm{~h}$ ), $1.2 \mathrm{~m} M$ fatty acids (cells treated with $1.2 \mathrm{~m} M$ fatty acids for $12 \mathrm{~h}$ ), DGAT1 inhibitor (cells treated with $0.3 \mu M$ DGAT1 inhibitor 2 for $12 \mathrm{~h}$ ), DGAT1 inhibitor $+1.2 \mathrm{~m} M$ fatty acids (cells treated with $0.3 \mu M$ DGAT1 inhibitor and 1.2 $\mathrm{m} M$ fatty acids for $12 \mathrm{~h}$ ), DGAT2 inhibitor (cells treated with $0.3 \mu M$ PF-06424439 for $12 \mathrm{~h}$ ), DGAT2 inhibitor $+1.2 \mathrm{~m} M$ fatty acids (cells treated with $0.3 \mu M$ PF-06424439 and $1.2 \mathrm{mM}$ fatty acids for $12 \mathrm{~h}$ ). (A) Relative mRNA abundance of SREBF1, FASN, DGAT1, DGAT2, CPT1A, MTTP, and APOB; (B) representative western blots of SREBF1, FASN, DGAT1, DGAT2, MTTP, and APOB; and (C) relative protein abundance of SREBF1, FASN, DGAT1, CPT1A, DGAT2, MTTP, and APOB. The data of the control were used to normalize other treatments. Treatment comparisons were assessed by one-way ANOVA and Holm's multiple comparison test to determine individual group differences. The data presented are the mean $\pm \mathrm{SEM} ;{ }^{*} P \leq 0.05,{ }^{*} P \leq 0.01$ indicate differences from control. \#P $\leq 0.05$, \#\#P $\leq 0.01$ indicate differences from fatty acids alone. 
Effect of Inhibition of DGAT1 and DGAT2 on Oxidative Stress and Endoplasmic Reticulum Stress

Relative mRNA and protein abundance of GRP78 and protein abundance of PERK in cells with both
DGAT1 and DGAT2 inhibitor with or without fatty acids were greater compared with the control and fatty acid groups $(P<0.01$; Figure $4 \mathrm{~A}-\mathrm{C})$.

Concentration of MDA was greater in hepatocytes receiving fatty acids compared with the control group $(P=0.020 ;$ Figure 4D). However, there were no marked

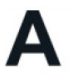

TAG
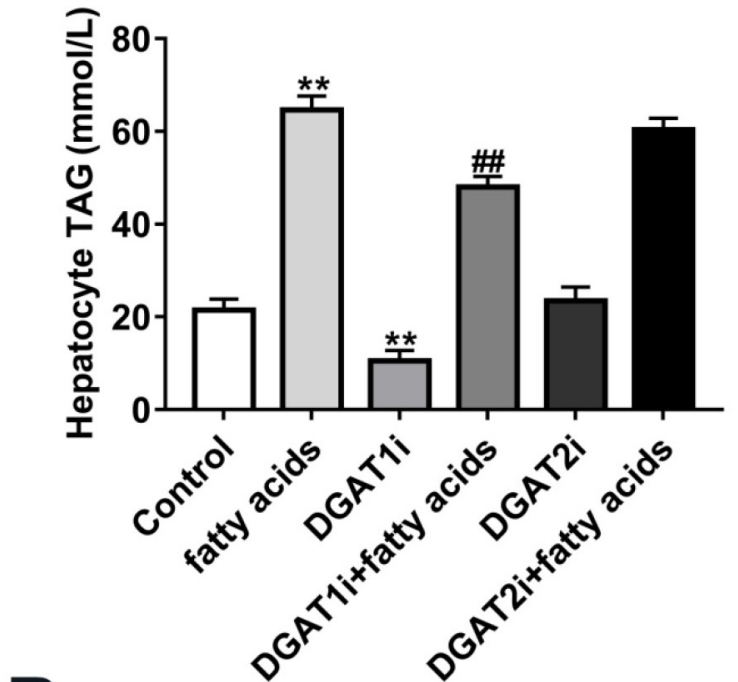

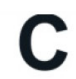

APOB lipid moiety

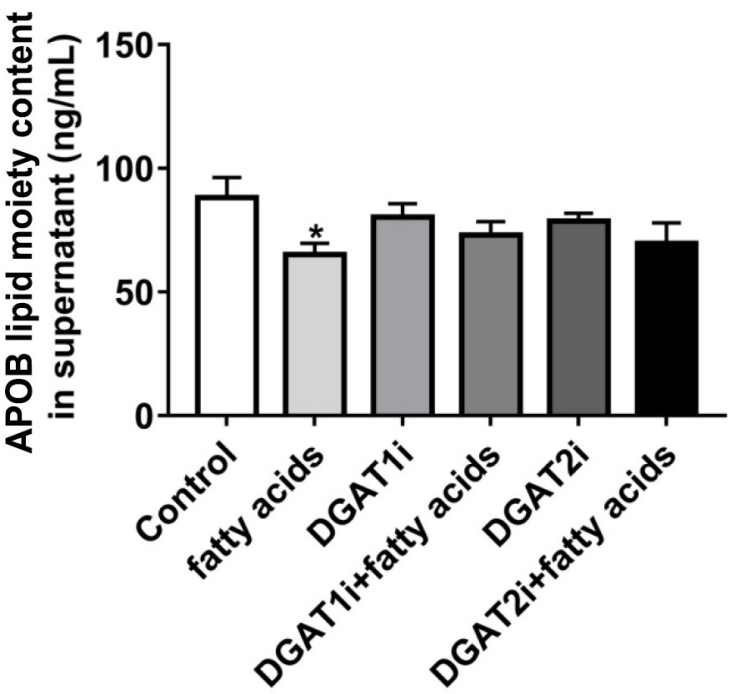

B

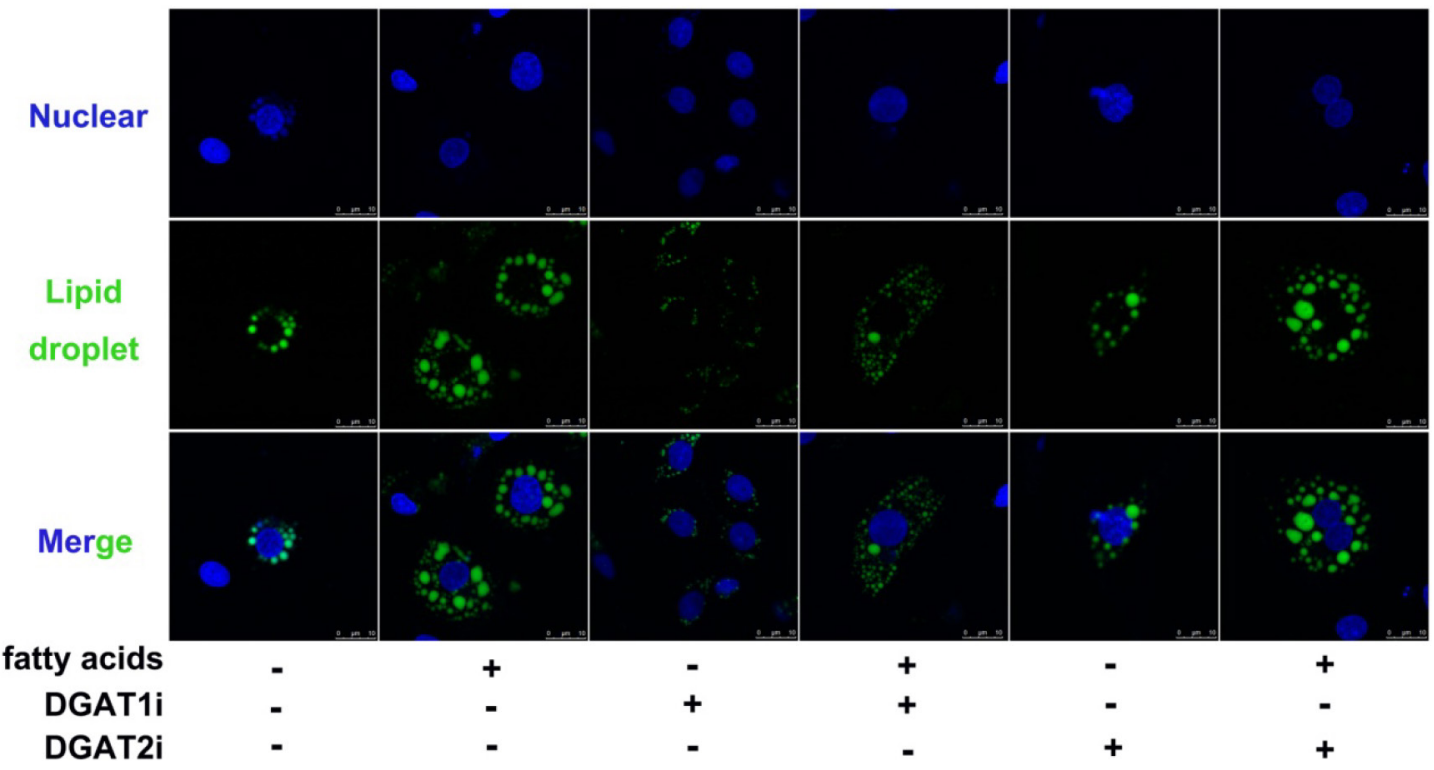

Figure 3. The effect of DGAT1 and DGAT2 inhibitor on triacylglycerol (TAG) concentration, APOB lipid moiety secretion, and immunofluorescence of lipid droplets in calf primary hepatocytes. Treatments were control group (cells cultured in RPMI-1640 basic medium for $12 \mathrm{~h}$ ), $1.2 \mathrm{~m} M$ fatty acids (cells treated with $1.2 \mathrm{~m} M$ fatty acids for $12 \mathrm{~h}$ ), DGAT1 inhibitor (cells treated with $0.3 \mu M$ DGAT1 inhibitor 2 for $12 \mathrm{~h}$ ), DGAT1 inhibitor $+1.2 \mathrm{~m} M$ fatty acids (cells treated with $0.3 \mu M$ DGAT1 inhibitor 2 and $1.2 \mathrm{~m} M$ fatty acids for $12 \mathrm{~h}$ ), DGAT2 inhibitor (cells treated with $0.3 \mu M$ PF-06424439 for $12 \mathrm{~h}$ ), and DGAT2 inhibitor $+1.2 \mathrm{~m} M$ fatty acids (cells treated with $0.3 \mu M$ PF-06424439 and $1.2 \mathrm{~m} M$ fatty acids for $12 \mathrm{~h}$ ). (A) TAG content in hepatocytes; (B) immunofluorescence results of lipid droplets; and (C) APOB lipid moiety content in the cell culture supernatant of primary hepatocytes. Immunofluorescence of lipid droplets, scale bar $=25 \mu \mathrm{m}$. Treatment comparisons were assessed by one-way ANOVA and Holm's multiple comparison test to determine individual group differences. The data presented are the mean $\pm \mathrm{SEM} ;{ }^{*} P \leq 0.05,{ }^{*} P \leq 0.01$ indicate differences from control. \#\#P $\leq 0.01$ indicate differences from fatty acids alone. 
A

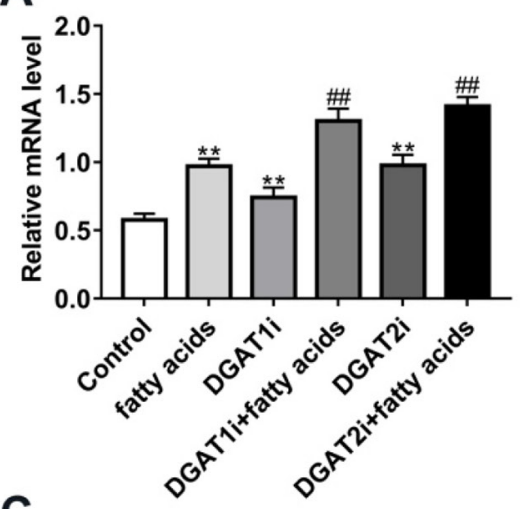

C

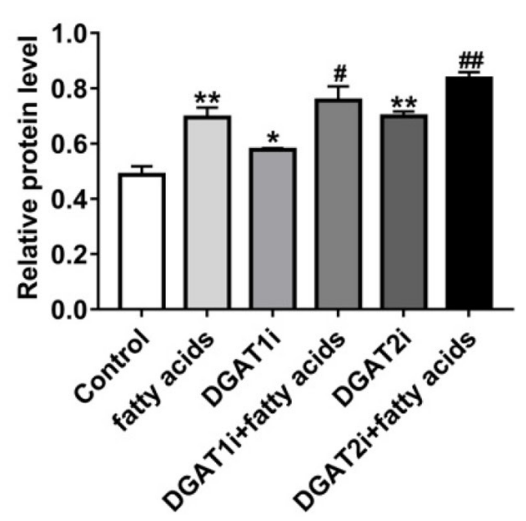

PERK

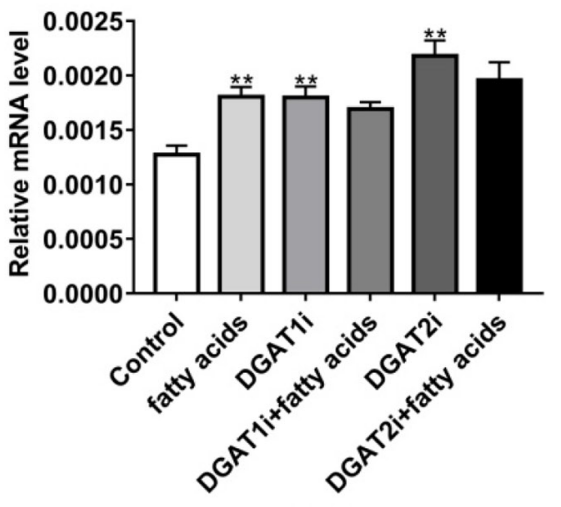

PERK

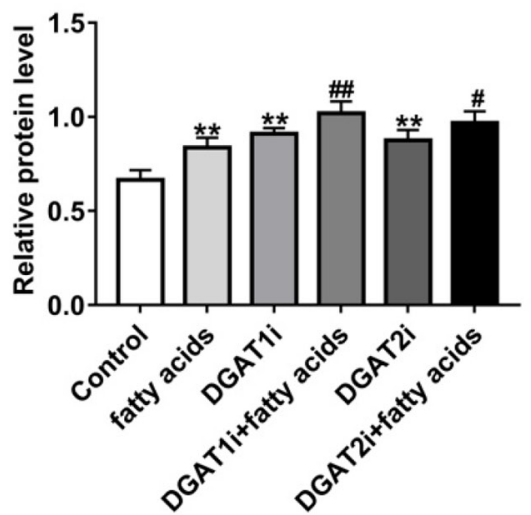

B
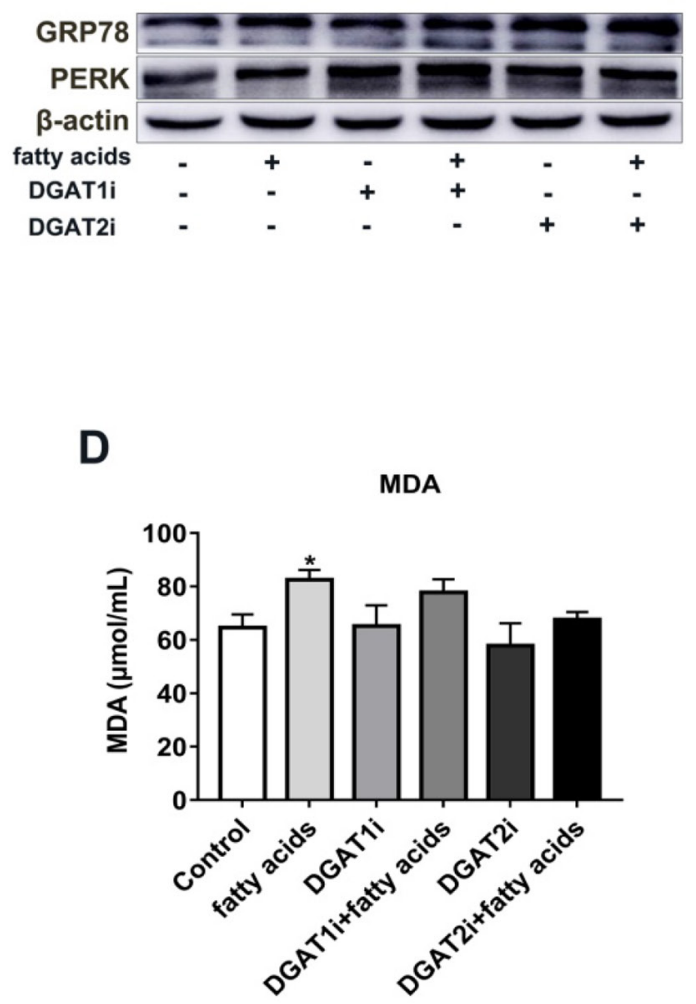

$\mathbf{F}$

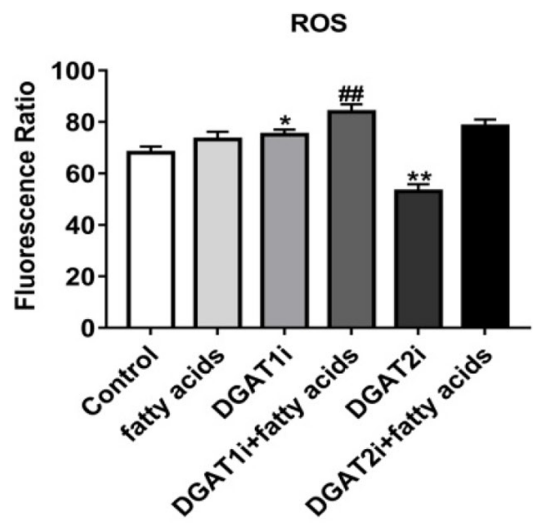

Figure 4. The effect of DGAT1 inhibitor 2 and PF-06424439 on oxidative stress and mitochondrial damage in calf primary hepatocytes culture supernatant. Treatments were a control group (cells cultured in RPMI-1640 basic medium for $12 \mathrm{~h}$ ), $1.2 \mathrm{~m} M$ fatty acids (cells treated with $1.2 \mathrm{~m} M$ fatty acids for $12 \mathrm{~h}$ ), DGAT1 inhibitor (cells treated with $0.3 \mu M$ DGAT1 inhibitor 2 for $12 \mathrm{~h}$ ), DGAT1 inhibitor $+1.2 \mathrm{~m} M$ fatty acids (cells treated with $0.3 \mu M$ DGAT1 inhibitor and $1.2 \mathrm{~m} M$ fatty acids for $12 \mathrm{~h}$ ), DGAT2 inhibitor (cells treated with $0.3 \mu M$ PF-06424439 for $12 \mathrm{~h}$ ), and DGAT2 inhibitor $+1.2 \mathrm{~m} M$ fatty acids (cells treated with $0.3 \mu M$ PF-06424439 and $1.2 \mathrm{~m} M$ fatty acids for $12 \mathrm{~h}$ ). (A) Relative mRNA abundance of GRP78 and PERK; (B) representative western blots of GRP78 and PERK; (C) relative protein abundance of GRP78 and PERK. (D) malondialdehyde (MDA) content in hepatocytes; (E) results of reactive oxygen species (ROS) flow cytometry; and (F) ROS content in hepatocytes. Treatment comparisons were assessed by one-way ANOVA and Holm's multiple comparison test to determine individual group

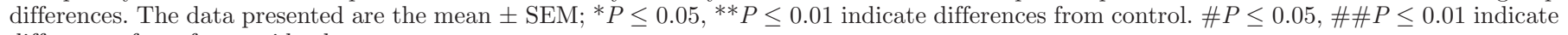
differences from fatty acids alone. 
changes in MDA concentration in hepatocytes with DGAT1 inhibitor and DGAT2 inhibitor compared with the control (Figure 4D).

Overall, compared with the control, ROS concentration was greater in hepatocytes with DGAT1 inhibitor $(P=0.030 ;$ Figure $4 \mathrm{E}-\mathrm{F})$. In contrast, compared with the control, concentration was lower in hepatocytes with DGAT2 inhibitor $(P<0.01$; Figure $4 \mathrm{E}-\mathrm{F})$. In addition, compared with the fatty acid group, ROS concentration was greater in hepatocytes with DGAT1 $(P<0.01)$ and DGAT2 inhibitor + fatty acids $(P<$ 0.01 ; Figure 4E-F).

\section{DISCUSSION}

Dairy cows are often afflicted by disorders related to fatty acid metabolism due to the state of NEB they face around parturition, which causes fatty acid mobili- zation from adipose tissue and liver lipid accumulation (van den Top et al., 1995; Du et al., 2018a; McFadden and Rico, 2019). In nonruminants, de novo fatty acid synthesis along with uptake of fatty acids from the circulation both contribute to TAG synthesis in the liver (Steenson et al., 2020). Recently studies with rodents, humans, and nonhuman primates reported that DGAT1 and DGAT2 are the major TAG synthesis regulatory proteins in hepatocytes (Hung et al., 2017; McLaren et al., 2018). Although differences among species might exist, the enzyme DGAT1 appears to prefer exogenous fatty acids for esterification, whereas DGAT2 uses mainly de novo synthesized fatty acids (McLaren et al., 2018). Unlike nonruminant species, mechanisms and specific roles of DGAT isoforms on lipid synthesis and metabolism in liver of dairy cows are still unclear. Thus, the present study evaluated characteristics of DGAT1 and DGAT2, and their related pathways in liver of

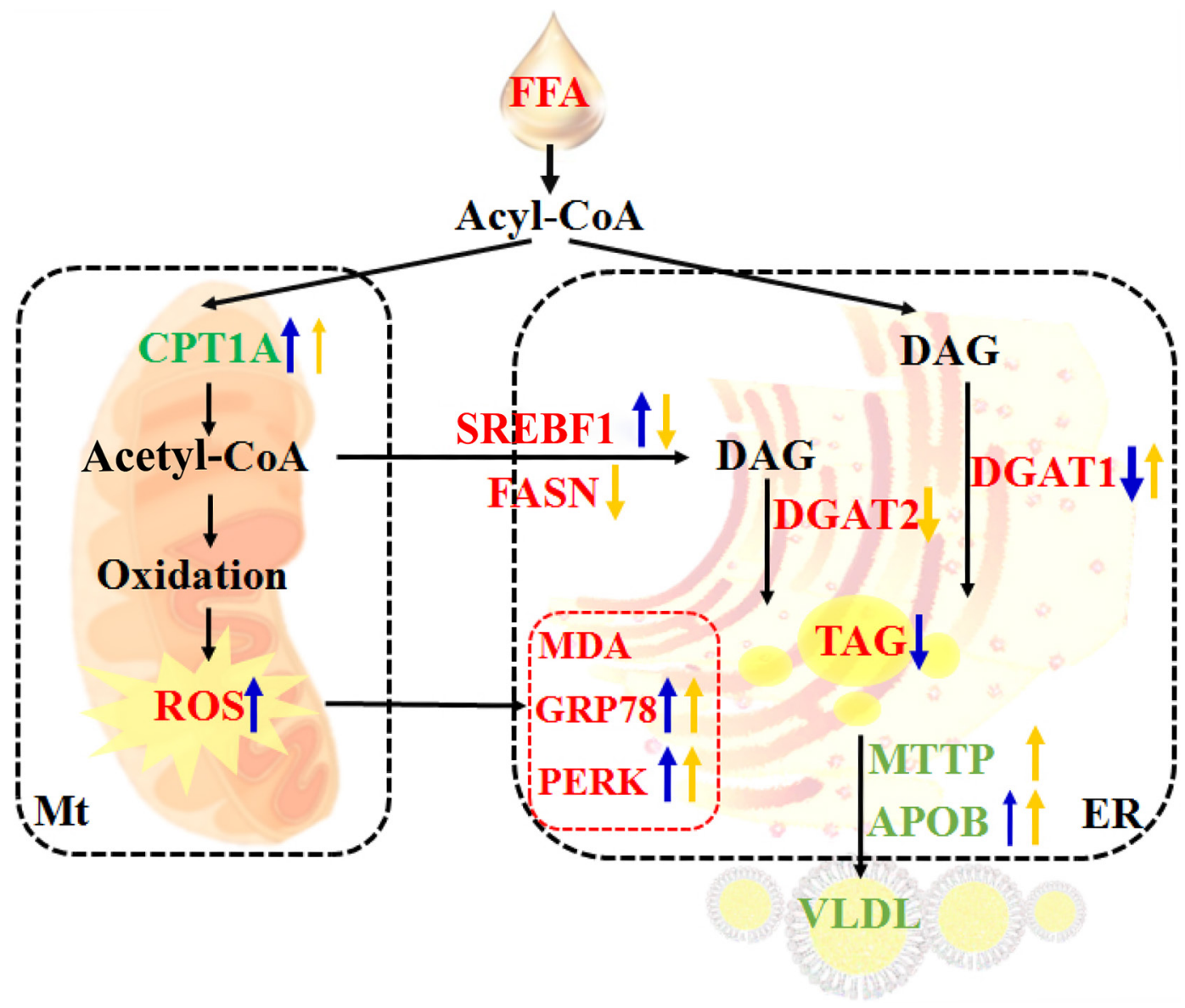

Figure 5. Schematic model illustrating the function of DGAT isoforms in regulating fatty acid metabolism in calf primary hepatocytes. Red and green $=$ high and low expression, respectively, in the fatty acid group compared with control group; upward and downward blue arrows $=$ high and low expression, respectively, with DGAT1 inhibition; upward and downward orange arrows: high and low expression, respectively, with DGAT2 inhibition. $\mathrm{Mt}=$ mitochondrion; $\mathrm{DAG}=$ diacylglycerol; $\mathrm{ER}=$ endoplasmic reticulum; FFA = free fatty acids; VLDL = very low-density lipoprotein; ROS = reactive oxygen species. 
dairy cows with fatty liver. Furthermore, primary calf hepatocytes were used to investigate more directly the regulation of DGAT1 and DGAT2.

Compared with healthy control cows, the markedly greater abundance of DGAT1 and DGAT2 in cows with fatty liver agrees with a previous study and indicated that de novo fatty acid synthesis and fatty acid esterification to form TAG promote lipid accumulation in dairy cows that developed fatty liver (van den Top et al., 1996). The fact that inhibition of DGAT1 markedly increased abundance of SREBF1, FASN, and DGAT2, whereas the opposite occurred when DGAT2 was inhibited, underscored the link between this DGAT and de novo fatty acid synthesis. Similar results were reported recently when DGAT2 was inhibited in hepatocytes from rhesus primates (McLaren et al., 2018). Clearly, data seem to suggest that DGAT2 and a lipogenic response can compensate in situations where DGAT1 activity is diminished (Figure 5).

It was noteworthy that, whereas inhibition of DGAT1 reduced TAG concentrations during the fatty acid challenge, the same effect was not observed when DGAT2 was inhibited. Indeed, inhibition of DGAT1 by antisense oligonucleotides prevented development of fatty liver in response to feeding a high-fat diet in mice (Chitraju et al., 2019). This approach to control liver lipid accumulation reportedly had multiple beneficial effects concerning obesity and diabetes phenotypes in mice (Smith et al., 2000). Contrary to these results, research in rodents and primates indicated that DGAT2 plays a more dominant role in hepatic TAG synthesis in rodents compared with primary human, rhesus, or cynomolgus hepatocytes following selective inhibition of DGAT2 (McLaren et al., 2018). Those data led us to suggest that (similar to humans), compared with the response of DGAT2 to the loss of DGAT1, DGAT1 activity might be able to compensate for the loss of DGAT2 activity in dairy cow liver.

It is well established that, compared with nonruminants, the VLDL (initial form of plasma APOB lipid moiety secreted by hepatocytes) secretion rate in ruminants is markedly lower, and especially during conditions that favor accumulation of TAG in the liver (Bauchart, 1993). Thus, the fact that APOB and MTTP abundances were markedly lower in liver tissue of cows with fatty liver explains in part the accumulation of TAG when fatty acids in the circulation increase. It is not entirely surprising that inhibition of DGAT1 and DGAT2 unenhanced APOB lipid secretion in response to exogenous fatty acids, but is important to note that inhibition of DGAT2 was particularly effective in increasing APOB and MTTP abundance after fatty acid challenge. The binding and lipid transfer activity of APOB and MTTP are one of the major determinants of VLDL secretion (Liu et al., 2014). In normal conditions, APOB synthesis is thought to far exceed its secretion, and when lipid binding decreases (e.g., in the absence of TAG), VLDL assembly decreases and APOB degradation increases (Cano et al., 2011). The reason for a lack of increase in APOB lipid secretion when DGAT2 was inhibited and abundance of APOB increased is not clear. It could be possible other events such as increased APOB degradation or other aspects of VLDL assembly and secretion in response to exogenous fatty acids were negatively affected by lack of DGAT2.

Fatty acid oxidation is a key biological process within the liver that helps regulate not only energy availability to liver cells, but also water-soluble fuels in the form of ketone bodies that peripheral tissues can use (Zhao et al., 2020). Activity of CPT1A regulates the entry of fatty acids into mitochondria before entry into $\beta$-oxidation (Li et al., 2013). Previous studies with cows experiencing moderate fatty liver and calf primary hepatocytes demonstrated that high concentration of fatty acids downregulated abundance of CPT1A (Dong et al., 2019). The fact that inhibition of DGAT1, not DGAT2, alleviated the upregulation in abundance of CPT1A induced by exogenous fatty acids suggested that it may might play a regulatory role in the channeling of fatty acids among cellular compartments. Studies in mouse liver and isolated hepatocytes reported that inhibition of DGAT1 resulted in greater flow of fatty acids into mitochondria for oxidation, leading to the generation of high levels of ROS, mitochondrial damage, cytochrome release, and apoptosis (Yamaguchi et al., 2008; Cheng et al., 2020). In the present study, inhibition of DGAT1 also increased markedly fatty acid-induced ROS concentrations, suggesting that that DGAT1-regulated TAG synthesis is a major pathway that competes with CPT1A for utilization of fatty acids for FA oxidation and ROS production. The aggravation of ER stress resulting from inhibition of DGAT1 and DGAT2 during the fatty acid challenge suggested that both enzymes (and especially DGAT1) play a dominant role in reducing the concentrations of free fatty acids to protect cells from oxidative damage.

The current studies on the liver metabolic mechanism of adult ruminants mostly rely on calf hepatocytes (Graulet et al., 1998; Fu et al., 2012; Weld et al., 2019; Zhang et al., 2020a). However, study has also shown that lipid metabolism efficiency is related to the age of nonruminant animals (Hahn et al., 2017). Therefore, caution should be exercised when attempting to infer animal liver metabolism in perinatal cows from hepatocytes of 1-d-old calves. Although in vitro data sug- 
gest that DGAT may affect lipid metabolism and TAG accumulation, the effects of DGAT on perinatal cows metabolism remain to be determined.

\section{CONCLUSIONS}

The process of TAG formation in hepatocytes especially when faced with high concentrations of fatty acids entails upregulating both DGAT1 and DGAT2 enzymes, which catalyze the last step in the esterification pathway. Inhibiting these enzymes, especially DGAT1, disrupts lipid homeostasis and results in channeling of fatty acids into mitochondria for oxidation, leading to generation of high levels of ROS along with mitochondrial damage. Thus, the high expression of DGAT1 in hepatocytes from cows experiencing fatty liver seems to play a dominant role in promoting fatty acid storage into TAG and lipid droplets to protect hepatocytes from oxidative damage.

\section{ACKNOWLEDGMENTS}

This work was supported by Chinese National Natural Science Foundation (U20A2062), Post-doctoral Startup Foundation in Heilongjiang (2020-51), China Agriculture Research System (CARS-36), and Young Innovative Talents Training Program of Ordinary Undergraduate Universities in Heilongjiang Province (no. UNPYSCT-2018081; Daqing, China). The authors have not stated any conflicts of interest.

\section{REFERENCES}

Bauchart, D. 1993. Lipid absorption and transport in ruminants. J. Dairy Sci. 76:3864-3881. https://doi.org/10.3168/jds.S0022 -0302(93)77728-0.

Bauchart, D., D. Gruffat, and D. Durand. 1996. Lipid absorption and hepatic metabolism in ruminants. Proc. Nutr. Soc. 55(1b):39-47. https://doi.org/10.1079/PNS19960010.

Bobe, G., J. W. Young, and D. C. Beitz. 2004. Invited review: Pathology, etiology, prevention, and treatment of fatty liver in dairy cows. J. Dairy Sci. 87:3105-3124. https://doi.org/10.3168/jds S0022-0302(04)73446-3.

Cano, A., X. Buque, M. Martinez-Una, I. Aurrekoetxea, A. Menor, J. L. Garcia-Rodriguez, S. C. Lu, M. L. Martinez-Chantar, J. M. Mato, B. Ochoa, and P. Aspichueta. 2011. Methionine adenosyltransferase $1 \mathrm{~A}$ gene deletion disrupts hepatic very low-density lipoprotein assembly in mice. Hepatology 54:1975-1986. https:// doi.org/10.1002/hep. 24607.

Cheng, X., F. Geng, M. Pan, X. Wu, Y. Zhong, C. Wang, Z. Tian, C. Cheng, R. Zhang, V. Puduvalli, C. Horbinski, X. Mo, X. Han, A. Chakravarti, and D. Guo. 2020. Targeting DGAT1 ameliorates glioblastoma by increasing fat catabolism and oxidative stress. Cell Metab. 32:229-242. https://doi.org/10.1016/j.cmet.2020.06.002.

Chitraju, C., T. C. Walther, and R. V. Farese Jr.. 2019. The triglyceride synthesis enzymes DGAT1 and DGAT2 have distinct and overlapping functions in adipocytes. J. Lipid Res. 60:1112-1120. https://doi.org/10.1194/jlr.M093112.

Coleman, D. N., M. Vailati-Riboni, A. A. Elolimy, F. C. Cardoso, S. L. Rodriguez-Zas, M. Miura, Y. X. Pan, and J. J. Loor. 2019. Hepatic betaine-homocysteine methyltransferase and methionine synthase activity and intermediates of the methionine cycle are altered by choline supply during negative energy balance in Holstein cows. J. Dairy Sci. 102:8305-8318. https://doi.org/10.3168/jds.2018-16204.

Dong, J., J. J. Loor, R. Zuo, X. Chen, Y. Liang, Y. Wang, X. Shu, X. Sun, H. Jia, G. Liu, Z. Wang, X. Li, and X. Li. 2019. Low abundance of mitofusin 2 in dairy cows with moderate fatty liver is associated with alterations in hepatic lipid metabolism. J. Dairy Sci. 102:7536-7547. https://doi.org/10.3168/jds.2019-16544.

Du, X., T. Shen, H. Wang, X. Qin, D. Xing, Q. Ye, Z. Shi, Z. Fang, Y. Zhu, Y. Yang, Z. Peng, C. Zhao, B. Lv, X. Li, G. Liu, and X. Li. 2018a. Adaptations of hepatic lipid metabolism and mitochondria in dairy cows with mild fatty liver. J. Dairy Sci. 101:9544-9558. https://doi.org/10.3168/jds.2018-14546.

Du, X., Y. Zhu, Z. Peng, Y. Cui, Q. Zhang, Z. Shi, Y. Guan, X. Sha, T. Shen, Y. Yang, X. Li, Z. Wang, X. Li, and G. Liu. 2018b. High concentrations of fatty acids and beta-hydroxybutyrate impair the growth hormone-mediated hepatic JAK2-STAT5 pathway in clinically ketotic cows. J. Dairy Sci. 101:3476-3487. https://doi.org/10 .3168/jds.2017-13234.

Fu, S., Q. Deng, W. Yang, H. Ding, X. Wang, P. Li, X. Li, Z. Wang, X. Li, and G. Liu. 2012. Increase of fatty acid oxidation and VLDL assembly and secretion overexpression of PTEN in cultured hepatocytes of newborn calf. Cell. Physiol. Biochem. 30:1005-1013. https://doi.org/10.1159/000341477.

Graulet, B., D. Gruffat, D. Durand, and D. Bauchart. 1998. Fatty acid metabolism and very low density lipoprotein secretion in liver slices from rats and preruminant calves. J. Biochem. 124:1212-1219. https://doi.org/10.1093/oxfordjournals.jbchem.a022240.

Grummer, R. R. 2007. Strategies to improve fertility of high yielding dairy farms: Management of the dry period. Theriogenology 68(Suppl 1):S281-S288. https://doi.org/10.1016/j.theriogenology .2007.04.031.

Hahn, O., S. Grönke, T. M. Stubbs, G. Ficz, O. Hendrich, F. Krueger, S. Andrews, Q. Zhang, M. J. Wakelam, A. Beyer, W. Reik, and L. Partridge. 2017. Dietary restriction protects from age-associated DNA methylation and induces epigenetic reprogramming of lipid metabolism. Genome Biol. 18:56. https://doi.org/10.1186/s13059 $-017-1187-1$

Hung, Y. H., A. L. Carreiro, and K. K. Buhman. 2017. Dgat1 and Dgat2 regulate enterocyte triacylglycerol distribution and alter proteins associated with cytoplasmic lipid droplets in response to dietary fat. Biochim. Biophys. Acta Mol. Cell Biol. Lipids 1862:600-614

Katoh, N. 2002. Relevance of apolipoproteins in the development of fatty liver and fatty liver-related peripartum diseases in dairy cows. J. Vet. Med. Sci. 64:293-307. https://doi.org/10.1292/jvms .64.293.

Li, M., W. Yang, J. Wen, J. J. Loor, A. Aboragah, J. Wang, S. Wang, M. Li, L. Yu, X. Hou, C. Xu, and B. Zhang. 2021. Intracellular $\mathrm{Ca} 2+$ signaling and ORAI calcium release-activated calcium modulator 1 are associated with hepatic lipidosis in dairy cattle. J. Anim. Sci. 99:skab184. https://doi.org/10.1093/jas/skab184.

Li, P., C. C. Wu, M. Long, Y. Zhang, X. B. Li, J. B. He, Z. Wang, and G. W. Liu. 2013. Short communication: high insulin concentrations inhibit fatty acid oxidation-related gene expression in calf hepatocytes cultured in vitro. J. Dairy Sci. 96:3840-3844. https:// doi.org/10.3168/jds.2012-6160.

Li, X., X. Li, G. Bai, H. Chen, Q. Deng, Z. Liu, L. Zhang, G. Liu, and Z. Wang. 2012. Effects of non-esterified fatty acids on the gluconeogenesis in bovine hepatocytes. Mol. Cell. Biochem. 359:385388. https://doi.org/10.1007/s11010-011-1032-x.

Liu, L., X. Li, Y. Li, Y. Guan, Y. Song, L. Yin, H. Chen, L. Lei, J. Liu, X. Li, Z. Wang, X. Yang, and G. Liu. 2014. Effects of nonesterified fatty acids on the synthesis and assembly of very low density lipoprotein in bovine hepatocytes in vitro. J. Dairy Sci. 97:1328-1335. https://doi.org/10.3168/jds.2013-6654.

Loor, J. J., M. Bionaz, and J. K. Drackley. 2013. Systems physiology in dairy cattle: Nutritional genomics and beyond. Annu. Rev. Anim. Biosci. 1:365-392. https://doi.org/10.1146/annurev-animal -031412-103728. 
McFadden, J. W., and J. E. Rico. 2019. Invited review: Sphingolipid biology in the dairy cow: The emerging role of ceramide. J. Dairy Sci. 102:7619-7639. https://doi.org/10.3168/jds.2018-16095.

McLaren, D. G., S. Han, B. A. Murphy, L. Wilsie, S. J. Stout, H. Zhou, T. P. Roddy, J. N. Gorski, D. E. Metzger, M. K. Shin, D. F. Reilly, H. H. Zhou, M. Tadin-Strapps, S. R. Bartz, A. M. Cumiskey, T. H. Graham, D. M. Shen, K. O. Akinsanya, S. F. Previs, J. E. Imbriglio, and S. Pinto. 2018. DGAT2 inhibition alters aspects of triglyceride metabolism in rodents but not in non-human primates. Cell Metab. 27:1236-1248. https://doi.org/10.1016/j.cmet 2018.04.004.

Murondoti, A., R. Jorritsma, A. C. Beynen, T. Wensing, and M. J. Geelen. 2004. Unrestricted feed intake during the dry period impairs the postpartum oxidation and synthesis of fatty acids in the liver of dairy cows. J. Dairy Sci. 87:672-679. https://doi.org/10 .3168/jds.S0022-0302(04)73210-5.

Qi, J., W. Lang, J. G. Geisler, P. Wang, I. Petrounia, S. Mai, C. Smith, H. Askari, G. T. Struble, R. Williams, S. Bhanot, B. P. Monia, S. Bayoumy, E. Grant, G. W. Caldwell, M. J. Todd, Y. Liang, M. D. Gaul, K. T. Demarest, and M. A. Connelly. 2012. The use of stable isotope-labeled glycerol and oleic acid to differentiate the hepatic functions of DGAT1 and -2. J. Lipid Res. 53:1106-1116. https://doi.org/10.1194/jlr.M020156.

Shahsavari, A., M. J. D'Occhio, and R. Al Jassim. 2016. The role of rumen-protected choline in hepatic function and performance of transition dairy cows. Br. J. Nutr. 116:35-44. https://doi.org/10 $.1017 /$ S0007114516001641.

Skrypina, N. A., A. V. Timofeeva, G. L. Khaspekov, L. P. Savochkina, and R. Beabealashvilli. 2003. Total RNA suitable for molecular biology analysis. J. Biotechnol. 105:1-9. https://doi.org/10.1016/ S0168-1656(03)00140-8.

Smith, S. J., S. Cases, D. R. Jensen, H. C. Chen, E. Sande, B. Tow, D. A. Sanan, J. Raber, R. H. Eckel, and R. V. Farese Jr.. 2000. Obesity resistance and multiple mechanisms of triglyceride synthesis in mice lacking Dgat. Nat. Genet. 25:87-90. https://doi.org/10 $.1038 / 75651$

Steenson, S., F. Shojaee-Moradie, M. B. Whyte, K. G. Jackson, J. A. Lovegrove, B. A. Fielding, and A. M. Umpleby. 2020. The effect of fructose feeding on intestinal triacylglycerol production and de novo fatty acid synthesis in humans. Nutrients 12:1781. https:// doi.org/10.3390/nu12061781.

Sturley, S. L., and M. M. Hussain. 2012. Lipid droplet formation on opposing sides of the endoplasmic reticulum. J. Lipid Res. 53:1800-1810. https://doi.org/10.1194/jlr.R028290.

Takahashi, N., F. Li, K. Hua, J. Deng, C. H. Wang, R. R. Bowers, T. J. Bartness, H. S. Kim, and J. B. Harp. 2007. Increased energy expenditure, dietary fat wasting, and resistance to diet-induced obesity in mice lacking renin. Cell Metab. 6:506-512. https://doi .org/10.1016/j.cmet.2007.10.011.

Vailati Riboni, M., S. Meier, N. V. Priest, C. R. Burke, J. K. Kay, S. McDougall, M. D. Mitchell, C. G. Walker, M. Crookenden, A. Heiser, J. R. Roche, and J. J. Loor. 2015. Adipose and liver gene expression profiles in response to treatment with a nonsteroidal antiinflammatory drug after calving in grazing dairy cows. J. Dairy Sci. 98:3079-3085. https://doi.org/10.3168/jds.2014-8579.

van den Top, A. M., M. J. Geelen, T. Wensing, G. H. Wentink, A. T. Van 't Klooster, and A. C. Beynen. 1996. Higher postpartum hepatic triacylglycerol concentrations in dairy cows with free rather than restricted access to feed during the dry period are associated with lower activities of hepatic glycerolphosphate acyltransferase. J. Nutr. 126:76-85. https://doi.org/10.1093/jn/126.1.76.

van den Top, A. M., T. Wensing, M. J. Geelen, G. H. Wentink, A. T. van't Klooster, and A. C. Beynen. 1995. Time trends of plasma lipids and enzymes synthesizing hepatic triacylglycerol during postpartum development of fatty liver in dairy cows. J. Dairy Sci. 78:2208-2220. https://doi.org/10.3168/jds.S0022-0302(95)76848 -5 .
Weld, K. A., S. J. Erb, and H. M. White. 2019. Short communication: Effect of manipulating fatty acid profile on gluconeogenic gene expression in bovine primary hepatocytes. J. Dairy Sci. 102:75767582. https://doi.org/10.3168/jds.2018-16150.

Yamaguchi, K., L. Yang, S. McCall, J. Huang, X. X. Yu, S. K. Pandey, S. Bhanot, B. P. Monia, Y. X. Li, and A. M. Diehl. 2008. Diacylglycerol acyltranferase 1 anti-sense oligonucleotides reduce hepatic fibrosis in mice with nonalcoholic steatohepatitis. Hepatology 47:625-635. https://doi.org/10.1002/hep.21988.

Yamdagni, S., and L. H. Schultz. 1970. Fatty acid composition of blood plasma lipids of normal and ketotic cows. J. Dairy Sci. 53:10461050. https://doi.org/10.3168/jds.S0022-0302(70)86343-3.

Ying, F., H. Gu, Y. Xiong, and B. Zuo. 2017. Analysis of differentially expressed genes in gastrocnemius muscle between DGAT1 transgenic mice and wild-type mice. BioMed Res. Int. 2017:5404682. https://doi.org/10.1155/2017/5404682.

Yli-Jokipii, K. M., U. S. Schwab, R. L. Tahvonen, J. P. Kurvinen, H. M. Mykkanen, and H. P. Kallio. 2003. Chylomicron and VLDL TAG structures and postprandial lipid response induced by lard and modified lard. Lipids 38:693-703. https://doi.org/10.1007/ s11745-003-1117-6.

Yu, Y. H., Y. Zhang, P. Oelkers, S. L. Sturley, D. J. Rader, and H. N. Ginsberg. 2002. Posttranscriptional control of the expression and function of diacylglycerol acyltransferase-1 in mouse adipocytes. J. Biol. Chem. 277:50876-50884. https://doi.org/10.1074/ jbc.M207353200.

Zhang, B., M. Li, W. Yang, J. J. Loor, Y. Liang, S. Wang, Y. Zhao, H. Guo, X. Ma, L. Yu, and C. Xu. 2020a. Mitochondrial dysfunction and endoplasmic reticulum stress in calf hepatocytes are associated with fatty acid-induced ORAI calcium release-activated calcium modulator 1 signaling. J. Dairy Sci. 103:11945-11956. https: //doi.org/10.3168/jds.2020-18684.

Zhang, B., M. Li, W. Yang, J. J. Loor, S. Wang, Y. Zhao, H. Guo, X. Ma, C. Xia, and C. Xu. 2020b. Orai calcium release-activated calcium modulator 1 (ORAI1) plays a role in endoplasmic reticulum stress in bovine mammary epithelial cells challenged with physiological levels of ketone bodies. J. Dairy Sci. 103:4691-4701. https: //doi.org/10.3168/jds.2019-17422.

Zhao, B., C. Luo, M. Zhang, F. Xing, S. Luo, S. Fu, and X. Sun. 2020. Knockdown of phosphatase and tensin homolog (PTEN) inhibits fatty acid oxidation and reduces very low density lipoprotein assembly and secretion in calf hepatocytes. J. Dairy Sci. 103:1072810741. https://doi.org/10.3168/jds.2019-17920.

Zhu, Y., G. Liu, X. Du, Z. Shi, M. Jin, X. Sha, X. Li, Z. Wang, and X. Li. 2019. Expression patterns of hepatic genes involved in lipid metabolism in cows with subclinical or clinical ketosis. J. Dairy Sci. 102:1725-1735. https://doi.org/10.3168/jds.2018-14965.

Zoni, V., R. Khaddaj, P. Campomanes, A. R. Thiam, R. Schneiter, and S. Vanni. 2021. Pre-existing bilayer stresses modulate triglyceride accumulation in the ER versus lipid droplets. eLife 10:e62886. https://doi.org/10.7554/eLife.62886.

\section{ORCIDS}

Wei Yang (ํ) https://orcid.org/0000-0003-3440-2190

Juan J. Loor @ https://orcid.org/0000-0003-1586-4365

Matheus G. Lopes $\odot$ https://orcid.org/0000-0003-3955-445X

Yingying Zhao ๑ https://orcid.org/0000-0001-6308-4043

Xinru Ma ๑ https://orcid.org/0000-0003-2392-8015

Ming Li ๑ https://orcid.org/0000-0001-8837-9964

Bingbing Zhang (® https://orcid.org/0000-0002-1869-9652

Chuang Xu • https://orcid.org/0000-0002-0377-1439 